\title{
Cyclodextrin-grafted electrospun cellulose acetate nanofibers via "Click" reaction for removal of phenanthrene
}

\author{
Asli Celebioglu ${ }^{\mathrm{a}, \mathrm{b}}$, Serkan Demirci ${ }^{\mathrm{a}, \mathrm{c}}$, Tamer Uyar ${ }^{\mathrm{a}, \mathrm{b}, *}$ \\ a UNAM-National Nanotechnology Research Center, Bilkent University, Ankara 06800, Turkey \\ ${ }^{\mathrm{b}}$ Institute of Materials Science and Nanotechnology, Bilkent University, Ankara 06800, Turkey

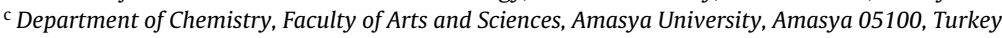

\section{A R T I C L E I N F O}

\section{Article history:}

Received 23 January 2014

Received in revised form 17 March 2014

Accepted 21 March 2014

Available online 29 March 2014

\section{Keywords:}

Electrospinning

Nanofibers

Cyclodextrin

"Click" reaction

Phenanthrene

Filtration

\begin{abstract}
A B S T R A C T
Beta-cyclodextrin ( $\beta$-CD) functionalized cellulose acetate $(C A)$ nanofibers have been successfully prepared by combining electrospinning and "click" reaction. Initially, $\beta-C D$ and electrospun CA nanofibers were modified so as to be azide- $\beta-C D$ and propargyl-terminated CA nanofibers, respectively. Then, "click" reaction was performed between modified CD molecules and CA nanofibers to obtain permanent grafting of CDs onto nanofibers surface. It was observed from the SEM image that, while CA nanofibers have smooth surface, there were some irregularities and roughness at nanofibers morphology after the modification. Yet, the fibrous structure was still protected. ATR-FTIR and XPS revealed that, CD molecules were successfully grafted onto surface of CA nanofibers. The adsorption capacity of $\beta$-CD-functionalized CA (CA-CD) nanofibers was also determined by removing phenanthrene (polycyclic aromatic hydrocarbons, $\mathrm{PAH}$ ) from its aqueous solution. Our results indicate that CA-CD nanofibers have potential to be used as molecular filters for the purpose of water purification and waste water treatment by integrating the high surface area of nanofibers with inclusion complexation property of $\mathrm{CD}$ molecules.
\end{abstract}

(ㄷ) 2014 Elsevier B.V. All rights reserved.

\section{Introduction}

Electrospun nanofibers/nanowebs possess several unique properties that make them good candidate for the filtration, separation and cleaning applications, such as; large specific surface area, highly porous structure with nano size range, high degree of interconnection and modifiable nature [1-5]. The potential of nanofibrous structure for filtration purposes has been reported in literature by showing separation of tiny particles, filtration of liquid medium [4-6] and waste vapor treatment $[3,7,8]$. Even, production variability, low-cost and high out-put of this technique make possible the filtration performance to enter into competition with conventional filtration systems. Moreover, electrospun nanofibers facilitate for chemical/physical functionalizations that can leads to better uptake performance during the filtration process [9-13].

Cyclodextrins (CDs) are natural cyclic oligosaccharides which are regenerated by the enzymatic degradation of starch. There are three native types of CD molecules; $\alpha-C D, \beta-C D$ and $\gamma-C D$ which are consisted of six, seven and eight glucopyranose subunits, respectively $[14,15]$. CDs have toroid-shaped molecular structure with a

\footnotetext{
* Corresponding author. Tel.: +90 3122903571; fax: +90 3122664365.

E-mail addresses: tamer@unam.bilkent.edu.tr, tameruyar@gmail.com (T. Uyar).
}

relatively hydrophobic interior cavity. Due to the intriguing molecular structure, CDs are able to form inclusion complexes (CD-IC) with a variety of molecules along with non-covalent interactions $[14,15]$. The inclusion complexation with CD molecules enhance solubility, stability and bioavailability of guest molecules. So, these CD-IC supramolecular structures are quite applicable in pharmaceuticals, foods, cosmetics, home/personal care and textiles areas [14-16]. Additionally, filtration and separation systems are another application fields for $\mathrm{CD}$ molecules owing to their capturing capability of hazardous organic molecules by inclusion complexation [17-20].

$\mathrm{CD}$ molecules are commonly utilized in the form of powder or crosslinked polymeric granules [14-16,20]. Unfortunately, this state can cause limitation during their usage. So, to benefit from CDs unique properties more efficiently and render them into more applicable form, they can be combined with polymeric matrix. In our previous studies, we have physically blended $\mathrm{CD}$ molecules into polymeric nanofibers by electrospinning $[7,21,22]$. It was observed that, while most of the $\mathrm{CD}$ molecules were embedded inside the nanofibers, some of them were located on the fiber surface and these accessible $\mathrm{CD}$ enable the removal of organic waste molecules from both vapor phase [7] and water-based environment [21,22]. However, water solubility of CDs restricts their use for water purification purposes, because of a probable leaching from nanofiber 
surface that can be occurred during filtration. Therefore, another approach should be adopted for the modification of nanofibers that includes the lasting attachments of $C D$ molecules on the fiber surface. Thus, complex formation property of $\mathrm{CD}$ molecules would be integrated with the high surface area of polymeric nanofibers in a more permanent way that would lead to production of promising filtering membranes. Actually, the chemical surface modification with $C D$ molecules was firstly performed on the fiber and fabric surfaces by using appropriate crosslinking agents [23-30]. These functionalizations were performed by grafting CDs onto substance [23-26] or the substances were covered by crosslinked CD polymers [27-30] for the filtration of waste molecules or delivery of drugs, antibacterials etc. On the other hand, we have firstly reported the surface modification of electrospun nanofibers with CD polymer in our previous study [31]. Here, citric acid was used as a crosslinking agent for the formation of $C D(\alpha-C D, \beta-C D$ and $\gamma-C D)$ polymer (CDP) and after the surface modification of polyethylene terephthalate (PET) nanofibers, the molecular filtration performance of PET/CDP was investigated as well [31].

Surface modified electrospun nanofibers are of great interest due to their higher potential for the application of aforementioned fields. Nanofibers functionalized in this way could be expected to increase their performance for the desired applications, since the availability of more active sides on their surface. "Click" chemistry can be an alternative way to modify surface of nanofibers, because "click" reactions show high yields and exceptional tolerance towards a wide range of functional groups and reaction conditions in the material science [32,33]. Very recent studies have also been reported in the literature about the modification of electrospun nanofibers via "click" reaction. For instance, $\mathrm{Fu}$ et al. formed thermal-sensitive poly-N-isopropylacrylamide (PNIPAM) brushes on the surface of poly(4-vinylbenzyl chloride)block-poly(glycidyl methacrylate) (PVBC-b-PGMA) nanofibers by using "click" reaction [34]. In another study of Chang et al., "click" was used for the functionalization of polyimide nanofibers via alkyne-terminated poly(methyl methacrylate) chains [35]. In the study of Yang et al. nanofibers having thermally sensitive surface were produced by the grafting of PNIPAM brushes on the poly((3mercaptopropyl)methylsiloxane) (PMMS) nanofibers with the aid of "click" chemistry [36]. In another related study, Lancuski et al. developed carbohydrate-decorated PCL nanofibers for the specific protein adhesion by applying "click" reaction [37]. In one of the associated studies, Qian et al. reported the introduction of saccharide residues to the surface of the polyphosphazene nanofibrous membrane using "click" chemistry [38]. Most of the studies mentioned above focus on the biomedical applications of nanofibers. On the other hand, in our study we have applied "click" reaction for surface modification of nanofibers to improve their filtration performance.

Polycyclic aromatic hydrocarbons (PAHs) are one of the most widespread pollutants which are highly toxic, carcinogenic, and their toxicity increases with increasing molecular weight [39]. Moreover, several studies show that PAHs pollutions cause serious health problems for human and living organisms [39,40]. For these reasons, varieties of adsorbents such as nanofibers, silica gel, porous nanoparticles etc., have been developed for the removal of PAHs $[31,41,42]$.

In this study, $\beta-C D$-functionalized CA nanofibers were successfully produced by combination of electrospinning and "click" chemistry (Fig. 1). That is, $\beta-C D$ was grafted onto electrospun CA nanofibers via "click" reaction. The morphological characterization of nanofibers were carried out by using scanning electron microscope (SEM). The surface characteristics of the nanofibers were investigated by attenuated total reflectance-Fourier transform infrared spectroscopy (ATR-FTIR) and x-ray photoelectron spectroscopy (XPS). Furthermore, the comparative molecular filtration performance of $\beta$-CD-functionalized CA nanofibers and pristine $C A$ nanofibers were investigated by removing phenanthrene (as a model $\mathrm{PAH}$ ) from the aqueous solutions. Our preliminary findings suggested that $\beta$-CD-functionalized CA nanofibers have potentials to be used as molecular filters for the purpose of water purification and/or waste water treatment by integrating the high surface area of the electrospun nanofibers with inclusion complexation property of CD molecules.

\section{Materials and methods}

\section{Materials}

Cellulose acetate (CA, Mw: 30000, 39.8 wt. \% acetyl, SigmaAldrich) dichloromethane (DCM, $\geq 99 \%$ (GC), Sigma-Aldrich), methanol ( $\geq 99.7 \%$ (GC), Sigma-Aldrich), beta-cyclodextrin $(\beta-C D)$ (Wacker Chemie AG), sodium hydroxide $(\mathrm{NaOH}$, Fluka, $\geq 98 \%$, small beads), acetonitrile (99.9\%, Sigma-Aldrich), p-toluenesulfonyl chloride (puriss., $\geq 99.0 \%$, Sigma-Aldrich) dimethyformamide ( $\geq 99 \%$ (GC), Sigma-Aldrich), sodium azide (ReagentPlus, $\geq 99.5 \%$, Sigma-Aldrich), sodium hydride (60\% dispersion in mineral oil, Aldrich), propargyl bromide solution ( $80 \%$ in toluene, Fluka), acetone ( $\geq 99 \%$ (GC), Sigma-Aldrich), 2-propanol ( $\geq 99.5 \%$ (GC), Sigma-Aldrich), copper sulfate (anhydrous, $\geq 99.0 \%$, Sigma-Aldrich), L-ascorbic acid (reagent grade, Sigma-Aldrich) phenanthrene (98\%, Sigma-Aldrich) were purchased. The water used was from a Millipore Milli-Q Ultrapure Water System. All the materials were used without any purification.

\section{Electrospinning of CA nanofibers}

The electrospinning solution of CA was prepared by dissolving polymer in a $\mathrm{DCM} /$ methanol $(4 / 1(\mathrm{v} / \mathrm{v}))$ binary solvent mixture at a $12 \%(\mathrm{w} / \mathrm{v})$ polymer concentration. The clear CA solution was then placed in a $5 \mathrm{~mL}$ syringe fitted with a metallic needle of a $0.4 \mathrm{~mm}$ inner diameter. The syringe was fixed horizontally on the syringe pump (model KDS-101, KDScientific, USA). The electrode of the high-voltage power supply (Spellman, SL30, USA) was clamped to the metal needle tip, and the plate-shaped aluminum collector was grounded. Electrospinning parameters were adjusted as follows: feed rate of solutions $=1 \mathrm{~mL} / \mathrm{h}$, applied voltage $=15 \mathrm{kV}$, tip-to-collector distance $=10 \mathrm{~cm}$. The electrospinning process was performed at $25^{\circ} \mathrm{C}$ at $20 \%$ relative humidity in Plexiglas box. After the electrospun nanofibers were deposited on the grounded metal collector covered with aluminum foil, they were kept in vacuum oven $\left(40^{\circ} \mathrm{C}\right)$ for almost $12 \mathrm{~h}$ to remove the solvent residual in the nanofibers.

\section{Synthesis of the azide- $\beta$-cyclodextrin}

$\beta-C D(63 \mathrm{~g}, 35.2 \mathrm{mmol}$ ) was dispersed in $500 \mathrm{~mL}$ of water and by the addition of $\mathrm{NaOH}$ solution ( $5.6 \mathrm{~g}$ in $20 \mathrm{ml}$ water), CDs were completely dissolved. After stirring $1 \mathrm{~h}$, the $p$-toluenesulfonyl chloride solution ( $9.5 \mathrm{~g}$ in $30 \mathrm{ml}$ acetonitrile) was dropped into $\mathrm{CD}$ solution slowly. The suspension was stirred vigorously for $6 \mathrm{~h}$ and kept in refrigerator overnight. The precipitate white powder was filtered and dried under vacuum (12 g TsO- $\beta-C D)$. In the second step, the TsO- $\beta-\mathrm{CD}(6 \mathrm{~g})$ powder was dissolved in DMF $(50 \mathrm{ml})$ and sodium azide $\left(\mathrm{NaN}_{3}, 2.75 \mathrm{~g}\right)$ was added into solution. This system was stirred at $80^{\circ} \mathrm{C}$ for about $24 \mathrm{~h}$ under nitrogen atmosphere and then, it was cooled to room temperature. Finally, the solution was dropped into cold acetone $(600 \mathrm{ml})$ and the white precipitate of the product was obtained after the filtration. 


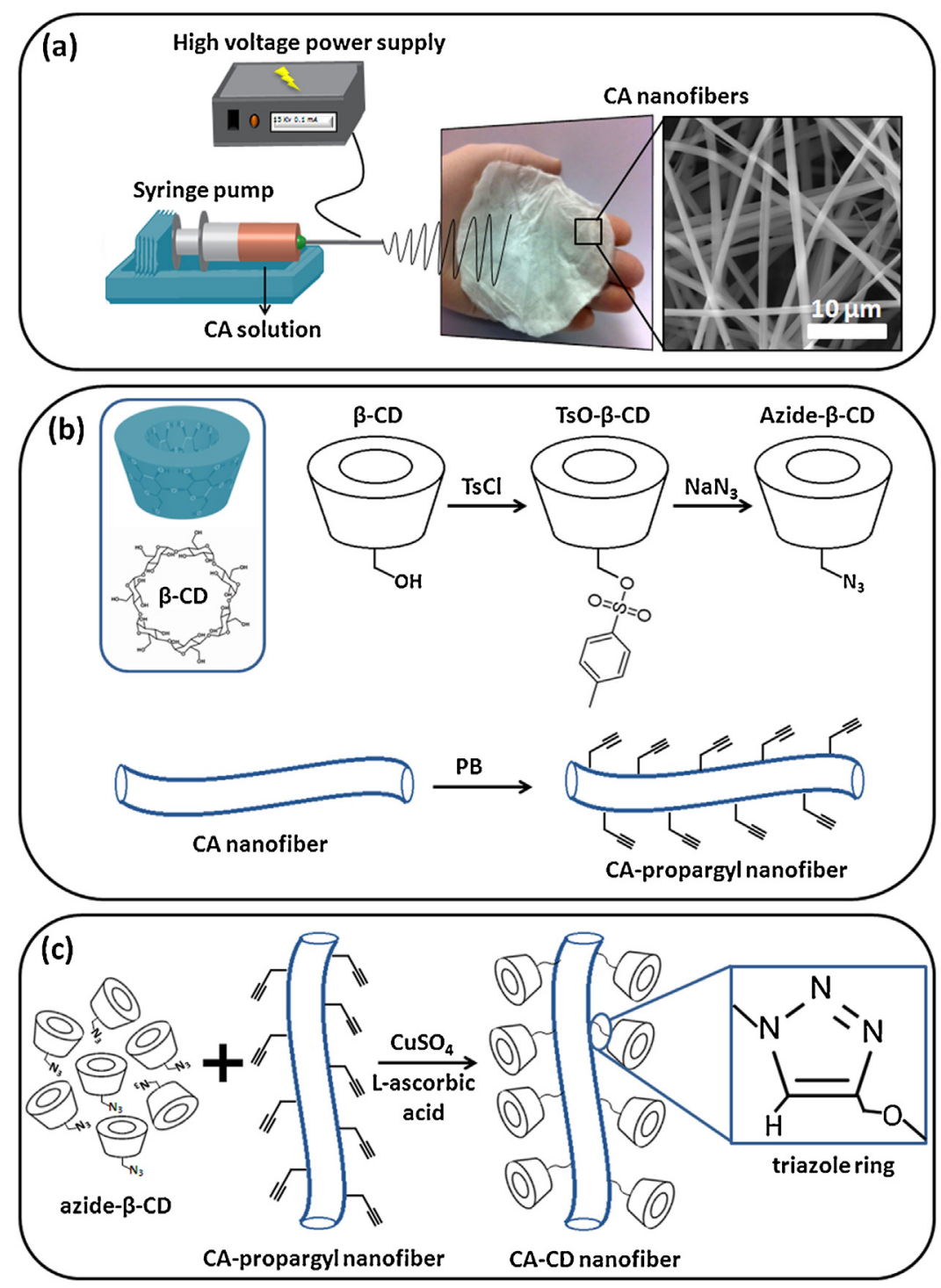

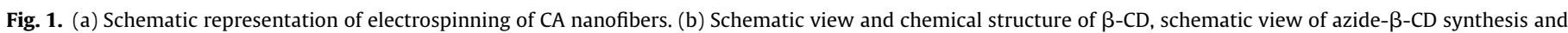
CA-propargyl nanofibers formation. (c) The schematic representation of the modification of CA-propargyl nanofibers with azide- $\beta$-CD by "click" reaction.

\section{Grafting of azide- $\beta$-CD onto CA nanofibers by “click” chemistry}

Under a nitrogen atmosphere, CA nanofibers (1.0 equiv.) and 2-propanol solution of $\mathrm{NaH}$ (1.2 equiv.) were added to a round bottomed flask at $0{ }^{\circ} \mathrm{C}$ and stirred for few minutes. The reaction mixture was gradually warmed to room temperature for $2 \mathrm{~h}$, and propargyl bromide (1.8 equiv.) was subsequently added dropwise. The resulting mixture was stirred at room temperature for $6 \mathrm{~h}$. The CA nanofibers were recovered from the reaction mixture and washed with 2-propanol and water to remove the unreacted chemicals, and dried under vacuum at $30^{\circ} \mathrm{C}$. The azide- $\beta-C D$ obtained in the former step $(0.6 \mathrm{mmol}, 0.7 \mathrm{~g})$ was firstly dissolved in $20 \mathrm{ml}$ water and CA nanofiber having propargyl moiety was put into this CD solution. Meanwhile, the fresh solutions of L-ascorbic acid $(0.12 \mathrm{mmol}, 21 \mathrm{mg})$ in $1.5 \mathrm{ml}$ water and copper (II) sulfate anhydrous $(0.052 \mathrm{mmol}, 8.8 \mathrm{mg}$ ) in $1.5 \mathrm{ml}$ water were prepared and both of them added into the solution which include azide- $\beta-C D$ and $C A-$ propargyl nanofibers. This system was stirred about $24 \mathrm{~h}$ at room temperature. Finally, obtained CA-CD nanofibers were removed from the solution, washed with water and dried at vacuum oven at $40^{\circ} \mathrm{C}$.

\section{Characterizations and measurements}

The morphological characterization and the diameter calculation of the CA, CA-propargyl and CA-CD nanofibers were performed by using scanning electron microscope (FE-SEM) (FEI, Quanta 200 FEG). Samples were sputtered with $5 \mathrm{~nm} \mathrm{Au} / \mathrm{Pd}$ (PECS-682) and around 100 fiber diameters were measured from the SEM images to calculate the average fiber diameter of each sample. The infrared spectra of the CDs were obtained by using a Fourier transform infrared spectrometer (FTIR) (Bruker-VERTEX 70). The samples were mixed with potassium bromide $(\mathrm{KBr})$ and pressed as pellets. The scans (64 scans) were recorded between 4000 and $400 \mathrm{~cm}^{-1}$ at a resolution of $4 \mathrm{~cm}^{-1}$. The Attenuated total reflectance-Fourier transform infrared (ATR-FTIR) was used for the surface structural analysis of nanofibers. ATR-FTIR spectra of the nanofibers were obtained using a Thermo Nicolet 6700 spectrometer with a Smart Orbit attenuated total reflection attachment. The spectra were taken at a resolution $4 \mathrm{~cm}^{-1}$ after 128 scan accumulation for an acceptable signal/noise ratio. The $\mathrm{x}$-ray photoelectron spectra of nanofibers were recorded by using $x$-ray photoelectron spectrometer (XPS) (Thermo Scientific). XPS was used by means of a flood 
gun charge neutralizer system equipped with a monochromated Al $\mathrm{K}-\alpha$ X-ray source $(h v=1486.6 \mathrm{eV})$. The high resolution spectra of $\mathrm{C}$ and $\mathrm{N}$ were also recorded for the related samples to get more detailed information. High performance liquid chromatography (HPLC) system (Agilent 1200 Series) was used to investigate the phenanthrene removing performance of both CA and CA-CD nanofibers. The separation of phenanthrene was performed with Zorbax Eclipse XDB-C18 column $(150 \mathrm{~mm} \times 4.6 \mathrm{~mm}, 5 \mu \mathrm{m}$ particle size) and it was detected at $254 \mathrm{~nm}$ wavelength. Acetonitrile (100\%) was used as mobile phase at a flow rate of $0.3 \mathrm{ml} / \mathrm{min}$. and the injection volume was kept at $10 \mu \mathrm{l}$. The phenanthrene was solved in acetonitrile and then diluted in water to carry out the measurements. The $0.1 \mathrm{~g}$ weighted nanofibers were immersed in $1.8 \mathrm{ppm}$ phenanthrene included water solutions $(30 \mathrm{ml})$ and $0.5 \mathrm{ml}$ aliquots were taken from the system at definite time intervals. The calibration curve of phenanthrene was prepared by using stock solutions in 4 different concentrations; $1.8 \mu \mathrm{g} / \mathrm{ml}, 0.9 \mu \mathrm{g} / \mathrm{ml} 0.45 \mu \mathrm{g} / \mathrm{ml}$, and $0.23 \mu \mathrm{g} / \mathrm{ml}$. It showed linearity and acceptability with $R^{2} \geq 0.99$. The measurement results were adapted to this calibration curve in terms of peak area under curves. The experiments were carried out in triplicate and the results were given with their standard deviations.

\section{Results and discussion}

Formation of azide- $\beta-C D$

The modification of the $\beta-C D$ molecules was confirmed by using FTIR spectra as illustrated in Fig. 2a. As seen, the characteristic absorption bands of $\beta-C D$ for the given three samples, appeared at around 1030,1080 , and $1155 \mathrm{~cm}^{-1}$ corresponding to the coupled $\mathrm{C}-\mathrm{C} / \mathrm{C}-\mathrm{O}$ stretching vibrations and asymmetric stretching vibration of the $\mathrm{C}-\mathrm{O}-\mathrm{C}$ glycosidic bridge. After $p$-toluenesulfonyl chloride treatment, beside the $\beta$-CD signals, toluenesulfonyl group characteristic bands were also observed as aromatic $C=C$ stretching at $1599 \mathrm{~cm}^{-1}, \mathrm{~S}=0$ stretching at $1366 \mathrm{~cm}^{-1}$ and $\mathrm{S}-\mathrm{O}-\mathrm{Ar}$ stretching at $838 \mathrm{~cm}^{-1}$ [43]. As a result of the next step, toluenesulfonyl group signals was disappeared in FTIR spectrum and stretching frequency of $\mathrm{N}_{3}$ became obvious at $2040 \mathrm{~cm}^{-1}$ demonstrating asymmetrical azide $\left(-\mathrm{N}_{3}\right)$ functionality of $\beta-C D$ [44].

\section{Morphological characterization of nanofibers}

The morphological behavior of CA nanofibers before and after the surface modification have been compared by SEM as depicted in Fig. 3. As it is shown in the SEM images, some changes were occurred at the morphology of CA nanofibers after each process. The uniform and smooth morphology was observed for un-modified CA nanofibers, whereas slight swelling was observed by the propargyl treatment (Fig. 3a and b). The rough and irregular appearance was recorded after the "click" reaction which proved the successful surface modification of CA nanofibers. The similar morphological change was also observed in a study of our research group in which the CD polymer was grafted on the PET nanofibers [31]. The overall results suggested that, adopted procedure did not cause to any deformation and fibrous structure of nanofibers was preserved during the chemical treatments. The average fiber diameters (AFD) were determined as $675 \pm 160,960 \pm 190$ and $1520 \pm 370$ for CA, CA-propargyl and CA-CD nanofibers, respectively. The increase of AFD could be originated from the swelling of nanofibers through the modification and/or irregular parts yielded as a result of $C D$ grafting.
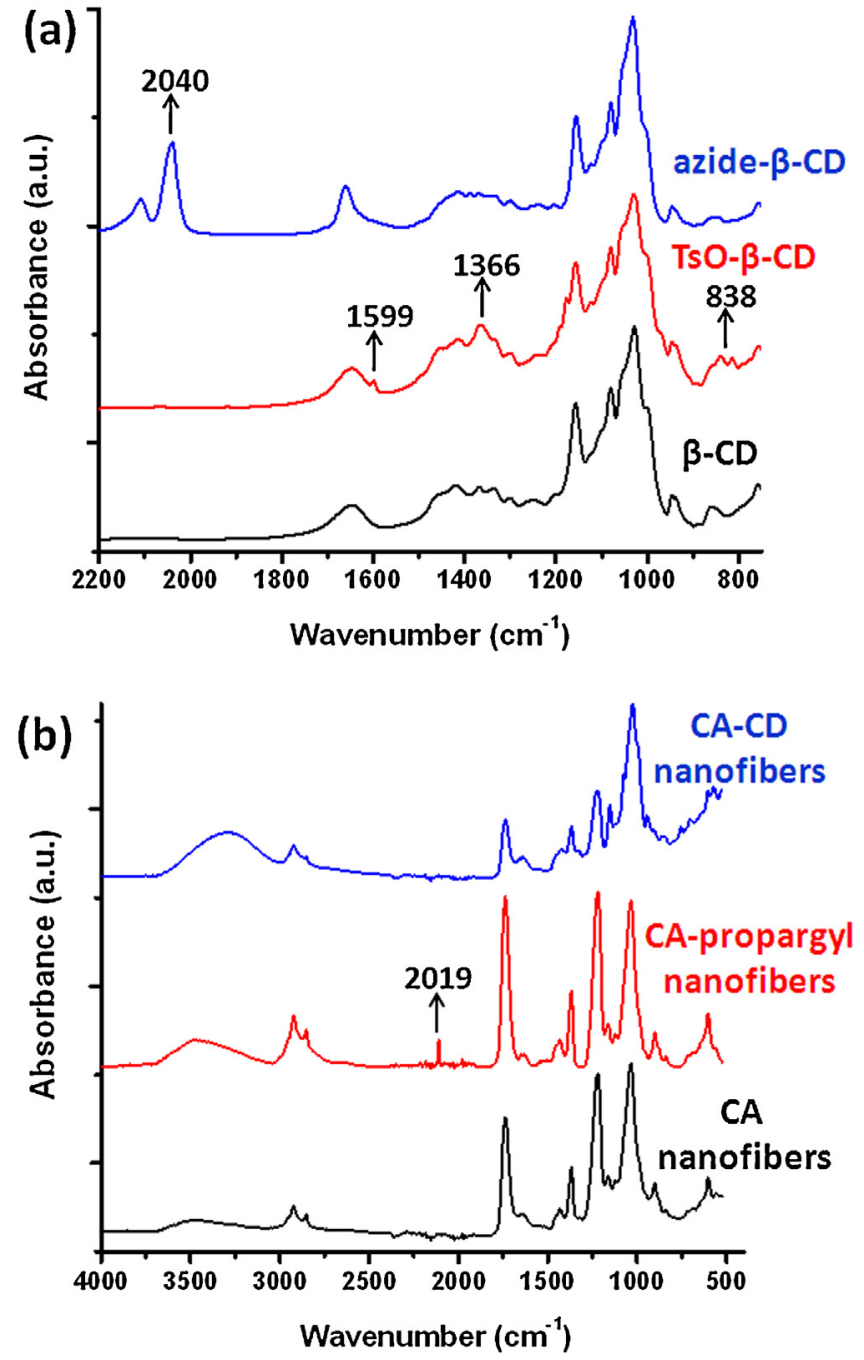

Fig. 2. (a) FTIR spectra of $\beta-C D$, TsO- $\beta-C D$ and azide- $\beta-C D$ powder, (b) ATR-FTIR spectra of CA, CA-propargyl and CA-CD nanofibers.

\section{Structural surface characterization of nanofibers}

The ATR-FTIR characterization was performed to prove the $C D$ modification on the nanofiber surface (Fig. 2b). The characteristic band of CA was observed at 1739 and $1221 \mathrm{~cm}^{-1}$ due to the $\mathrm{C}=\mathrm{O}$ and $\mathrm{C}-\mathrm{O}$ stretching, respectively. The broad band at $3700-3100 \mathrm{~cm}^{-1}$ indicates the presence of $\mathrm{OH}$ group in the CA structure. FTIR spectrum of CA also showed absorbance band at 2924 and $2855 \mathrm{~cm}^{-1}$ for the $\mathrm{C}-\mathrm{H}$ stretching. Initially, CA nanofibers were modified with propargyl bromide. This modification was obvious from the appearance of $C \equiv C$ band at $2019 \mathrm{~cm}^{-1}$ in the ATR-FTIR spectrum (Fig. 2b). Then, azide- $\beta-C D$ was attached to the CA-propargyl nanofiber surface by a "click" reaction and accordingly, the $\mathrm{C} \equiv \mathrm{C}$ band at $2019 \mathrm{~cm}^{-1}$ and $\mathrm{N}_{3}$ at $2040 \mathrm{~cm}^{-1}$ disappeared [45,46]. Furthermore, all characteristic bands of CA and CD were observed for the CA-CD nanofibers (Fig. 2b).

The surface of the CA, CA-propargyl and CA-CD nanofibers were also characterized by using XPS wide scan and high resolution scans to verify the functionalization of these samples. Table 1 summarizes the compositional percentages of nanofibers which were obtained as a result of wide energy survey scan. It was observed that, $\mathrm{C} 1 \mathrm{~s}$ and $\mathrm{O} 1 \mathrm{~s}$ are two intensive elements as the main compositions of nanofibers. For un-modified CA nanofibers, the ratio of $C$ $1 \mathrm{~s}: 01 \mathrm{~s}$ is $62.77: 37.23(\%)$, whereas for CA-propargyl, the intensity of $\mathrm{C} 1 \mathrm{~s}$ increase (C $1 \mathrm{~s}: 0$ 1s is $71.21: 28.79(\%)$ ) due to contribution 

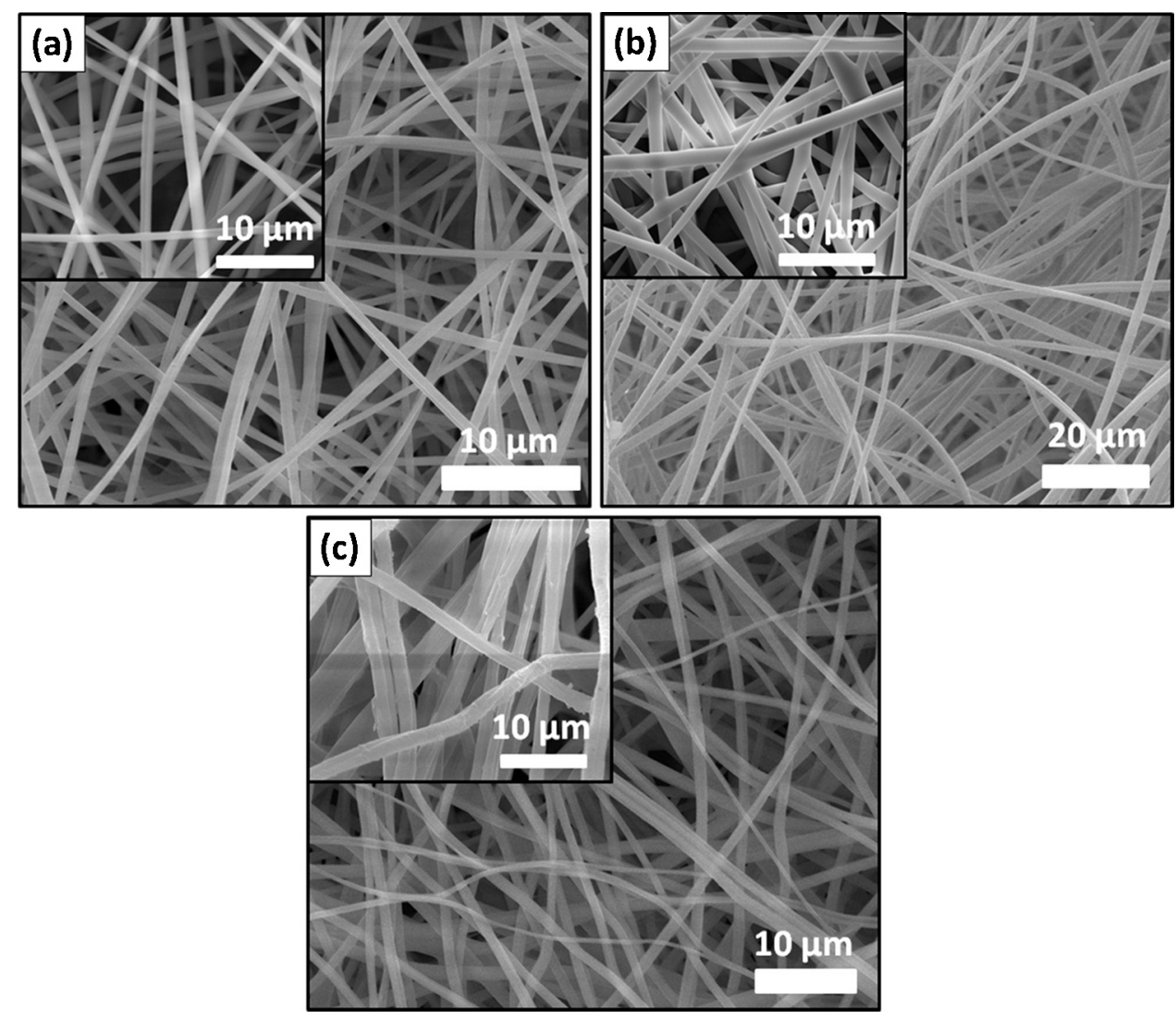

Fig. 3. Representative SEM images of (a) CA, (b) CA-propargyl and (c) CA-CD nanofibers. The insets show higher magnification images.
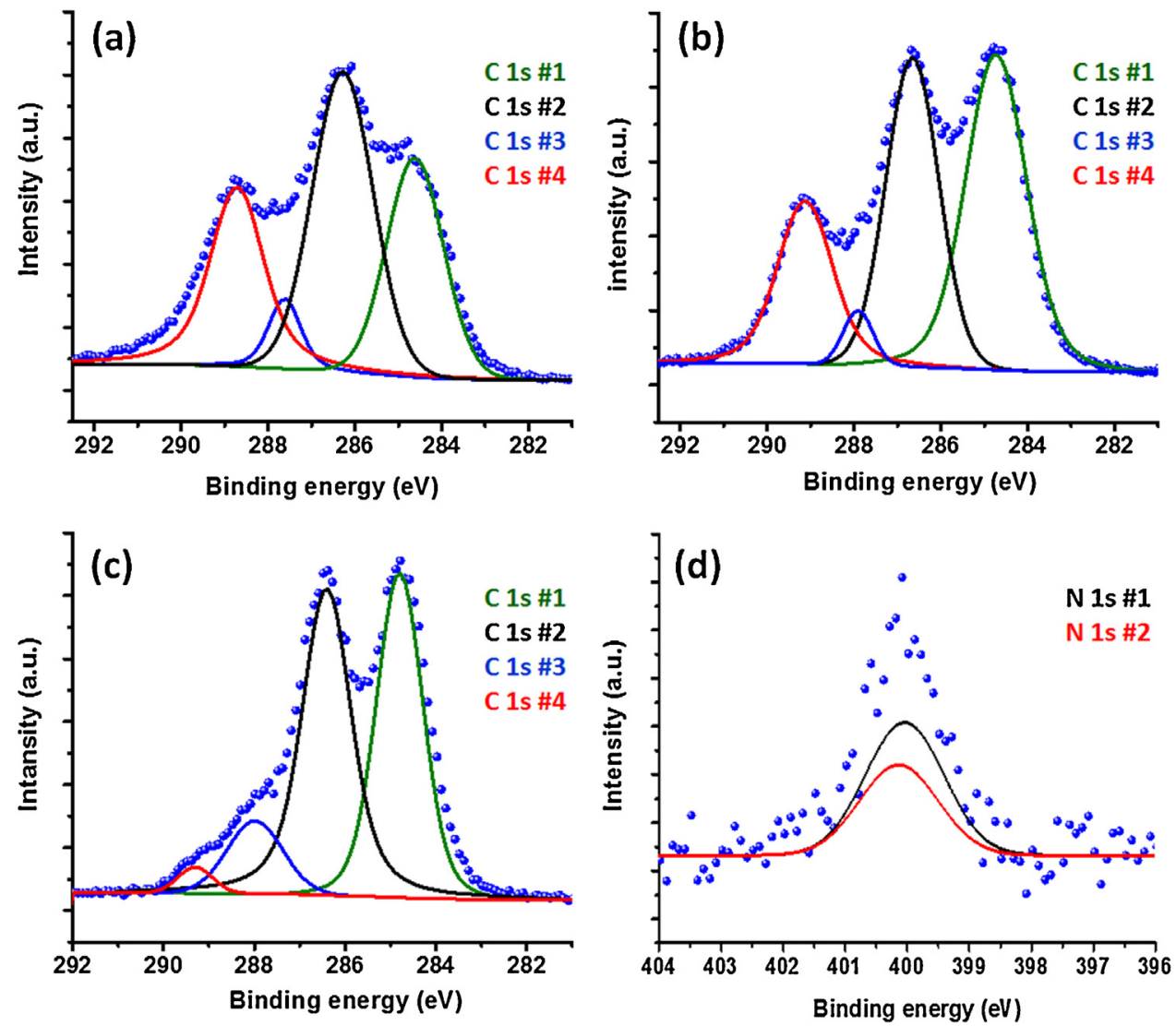

Fig. 4. High resolution C 1s XPS spectra of (a) CA, (b) CA-propargyl and (c) CA-CD nanofibers. (d) High resolution N 1s XPS spectrum of CA-CD nanofibers. 
Table 1

Atomic concentrations of nanofibers which were obtained from XPS wide energy survey scans.

\begin{tabular}{llll}
\hline Samples & $\mathrm{C}(\%)$ & $\mathrm{O}(\%)$ & $\mathrm{N}(\%)$ \\
\hline CA nanofibers & 62.77 & 37.23 & - \\
CA-propargyl nanofibers & 72.21 & 28.79 & - \\
CA-CD nanofibers & 72.75 & 25.58 & 1.67 \\
\hline
\end{tabular}

of $\mathrm{CH}_{2} \mathrm{C} \equiv \mathrm{CH}$ group in the first step of modification [47]. After "click" reaction, $\mathrm{N} 1 \mathrm{~s}$ was also recorded as one of the component which indicates the successful formation of trizole ring between CA nanofiber surface and CD molecules [48]. High resolution C 1s scan was performed to get more detailed information about the chemical state of nanofibers' surface. Fig. $4 a-c$ shows $C 1$ s spectra of un-modified CA, CA-propargyl and CA-CD nanofibers with their subpeaks obtained by fitting. In addition, the high resolution scan of $\mathrm{N} 1 \mathrm{~s}$ is given in Fig. 4d that belongs to CA-CD nanofibers. The corresponding positions of peak binding energies and their values (\% area ratio) were also listed in Table 2 . For un-modified CA nanofibers, $\mathrm{C}$ $1 \mathrm{~s}$ spectrum is deconvoluted into four subpeaks assigned to $\mathrm{C}-(\mathrm{C}$, $\mathrm{H}$ ) at $284.62 \mathrm{eV}, \mathrm{C}-\mathrm{O}$ at $286.28 \mathrm{eV}, \mathrm{O}-\mathrm{C}-\mathrm{O}$ at $287.62 \mathrm{eV}$ and $\mathrm{O}=\mathrm{C}-\mathrm{O}$ at $289.22 \mathrm{eV}$ [49]. After the first step of modification, the $\mathrm{C} 1 \mathrm{~s}$ spectrum (Fig. 4b) clearly shows increase of $\mathrm{C}-(\mathrm{C}-\mathrm{H})$ peak ratio from $30.45 \%$ to $43.21 \%$ and decrease of other peaks (Table 2) due to the grafting of $\mathrm{CH}_{2} \mathrm{C} \equiv \mathrm{CH}$ moiety [47]. This evidence made it possible to go to next step of CA nanofibers functionalization. In the case of azide- $\beta-C D$ grafting, the peak ratios of $\mathrm{C}-\mathrm{O}$ and $\mathrm{O}-\mathrm{C}-\mathrm{O}$ situated at 286.66 and 287.91 , respectively increased, on the other hand, the chemical state of $\mathrm{O}=\mathrm{C}-\mathrm{O}$ at $289.13 \mathrm{eV}$ decreased significantly owing to the location of $\beta-C D$ on the nanofiber surface (Fig. 4c, Table 2 ). In addition to $C 1 \mathrm{~s}$ peak, the $\mathrm{N} 1 \mathrm{~s}$ peak was also detected at about $400 \mathrm{eV}$ for $\mathrm{CA}-\mathrm{CD}$ nanofibers originated from the triazole group as a result of "click" reaction [48]. For triazole ring, the N 1s core-level peak can be curve-fitted into two components having binding energy at 398.4 and $399.7 \mathrm{eV}$ attributed to $\mathrm{C}-\mathrm{N}$ and $\mathrm{N}=\mathrm{N}$, respectively $[48,50]$. From XPS measurements, it was also confirmed that the surface modification of CA nanofibers with CD molecules was achieved by using "click" chemistry. In addition, the grafting density of CD molecules onto CA nanofibers were calculated from high resolution XPS spectra of $\mathrm{C} 1 \mathrm{~s}$. For this, $\mathrm{O}-\mathrm{C}-\mathrm{O}$ peak originated from both $C A$ and $C D$, and $O=C-O$ peak only existing in the $C A$ structure were chosen and used. The peak ratio $(\mathrm{O}-\mathrm{C}-\mathrm{O} / \mathrm{O}=\mathrm{C}-\mathrm{O})$ belongs to $\mathrm{CA}$ nanofiber was calculated as 0.72 and it is relatively close to the theoretical values $(0.80)$ calculated from atomic composition of CA nanofibers. On the other hand, $\mathrm{O}-\mathrm{C}-\mathrm{O} / \mathrm{O}=\mathrm{C}-\mathrm{O}$ ratio was determined as 4.55 for CA-CD nanofibers. As it is known, each $\beta-C D$ molecules have 7 glucopyranose subunits and after the click reaction, $\mathrm{O}-\mathrm{C}-\mathrm{O}$ peak area ratio increased by 6.32 times, which means that each $\beta-C D$ molecule was approximately bound to one repeat units of the CA positioned at nanofiber surface.

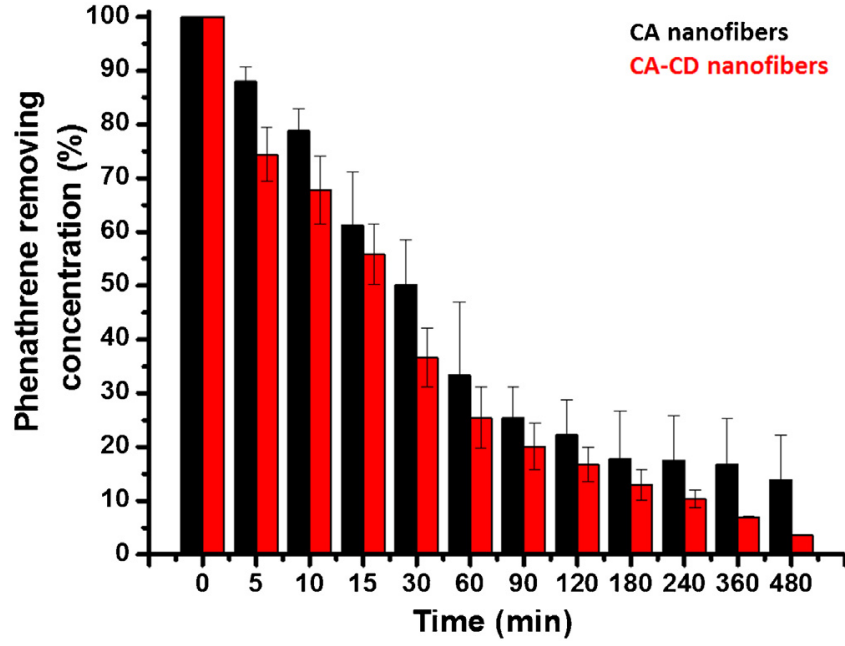

Fig. 5. The time dependent decrease of phenanthrene concentration in aqueous solution which contains CA and CA-CD nanofibers webs.

\section{Molecular filtration capability of $C A$ and $C A-C D$ nanofibers}

PAHs are important organic pollutants because of their mutagenic and carcinogenic potentials. However, the low-water solubility of these components limits the remediation process of contaminated water and soil $[39,40]$. As it is known, CDs are capable of encapsulating organic compounds due to their hydrophobic cavity and there are many studies reported complexation between CDs and PAHs molecules [51-55]. Phenanthrene is the most commonly known example through other hydrocarbons, so in this study, it was chosen as a model PAH to examine the molecular filtration potential of CA and CA-CD nanofibers. Fig. 5 depicts the cumulative decrease of phenanthrene concentration (\%) against progressing time intervals while $C A$ and $C A-C D$ nanofibers were being kept into this organic compound aqueous solution. As it is seen, the adsorption of phenanthrene was achieved by both CA and CA-CD nanofibers. Even, in the first $30 \mathrm{~min}$, while CA nanofibers removed $50 \%$ of phenanthrene from the solution, this ratio reached to $64 \%$ for CD-CA nanofibers. Towards the end of experiment, the differences of adsorbed amount between CA and CA-CD nanofibers increase, therefore phenanthrene concentration decreased more significantly for CA-CD nanofibers compared to un-modified CA nanofibers. The higher removing efficiency of $C D-C A$ nanofibers is probably originated from the inclusion complexation property of CD molecules which were located on the surface of nanofibers and leaded to higher adsorption of organic compound from aqueous medium. It is known that, hydrophobic interactions are the relation type between CDs cavity and phenanthrene molecule during the inclusion complexation. Besides, repulsive interactions between

Table 2

Fitting parameters of the C 1s XPS spectra of CA, CA-propargyl and CA-CD nanofibers.

\begin{tabular}{|c|c|c|c|c|}
\hline Samples & Fitting peaks & Bonds & Peak binding energy $(\mathrm{eV})$ & Area ratio (\%) \\
\hline \multirow[t]{4}{*}{ CA nanofibers } & C 1s \#1 & $\mathrm{C}-(\mathrm{C}-\mathrm{H})$ & 284.62 & 30.45 \\
\hline & C $1 \mathrm{~s} \# 2$ & $\mathrm{C}-\mathrm{O}$ & 286.28 & 20.32 \\
\hline & C 1s \#3 & $\mathrm{O}-\mathrm{C}-\mathrm{O}$ & 287.62 & 20.61 \\
\hline & C $1 \mathrm{~s} \# 4$ & $\mathrm{O}=\mathrm{C}-\mathrm{O}$ & 289.22 & 28.62 \\
\hline \multirow[t]{4}{*}{ CA-propargyl nanofibers } & C 1s \#1 & $\mathrm{C}-(\mathrm{C}-\mathrm{H})$ & 284.73 & 43.21 \\
\hline & C $1 s \# 2$ & $\mathrm{C}-\mathrm{O}$ & 286.66 & 20.29 \\
\hline & C $1 \mathrm{~s} \# 3$ & $\mathrm{O}-\mathrm{C}-\mathrm{O}$ & 287.91 & 5.37 \\
\hline & C $1 \mathrm{~s} \# 4$ & $\mathrm{O}=\mathrm{C}-\mathrm{O}$ & 289.13 & 13.74 \\
\hline \multirow[t]{4}{*}{ CA-CD nanofibers } & C 1s \#1 & $\mathrm{C}-(\mathrm{C}-\mathrm{H})$ & 284.80 & 43.13 \\
\hline & C $1 \mathrm{~s} \# 2$ & $\mathrm{C}-\mathrm{O}$ & 286.41 & 45.09 \\
\hline & C $1 \mathrm{~s} \# 3$ & $\mathrm{O}-\mathrm{C}-\mathrm{O}$ & 287.99 & 9.66 \\
\hline & C $1 \mathrm{~s} \# 4$ & $\mathrm{O}=\mathrm{C}-\mathrm{O}$ & 289.30 & 2.12 \\
\hline
\end{tabular}



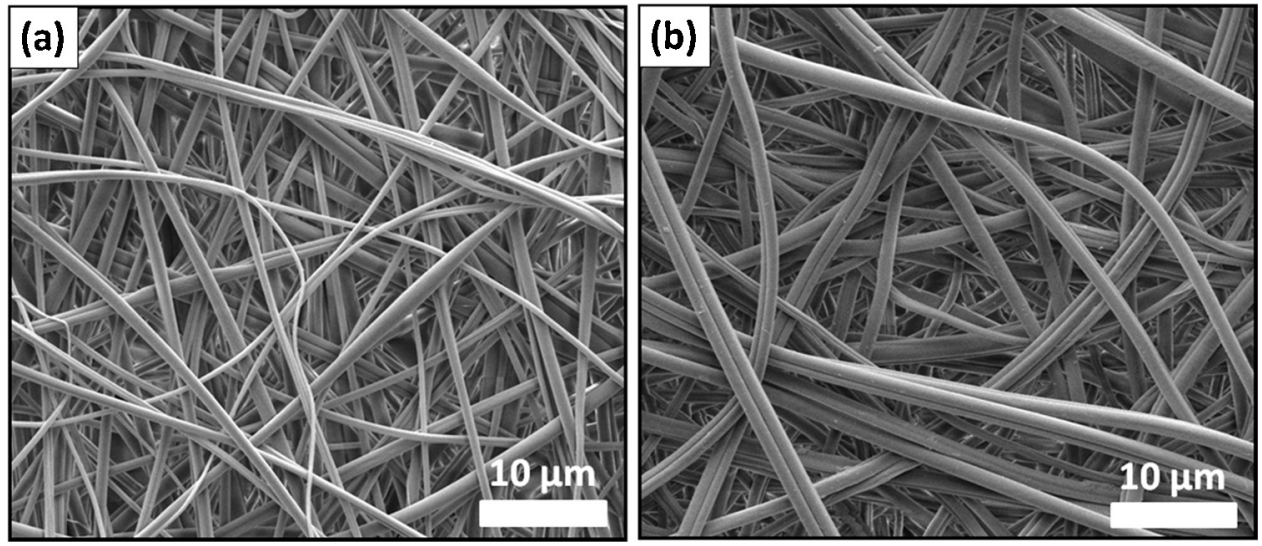

Fig. 6. Representative SEM images of (a) CA and (b) CA-CD nanofibers after the filtration test.

the hydrophobic guest and the aqueous environment, and more favorable interactions between hydrophobic guest and apolar CD cavity are the driving forces for the removing of phenanthrene molecules from the aqueous environment [16-53]. In the case of $\mathrm{CD}$ grafting onto nanofibers surface, only $\mathrm{CD}$ molecules become more applicable compared to their powder form by the location on a stable carrier matrix. However, it does not cause any change at the entrapment and removing mechanism of phenanthrene molecules by CDs. Here, it was also observed that, both CA and CA-CD nanofibers still kept their fiber structure after the filtration test (Fig. 6). CA is already good candidate for the filtration of organic pollutants and there are also reports in the literature about the uptaking of PAHs from the concerned environment by using CA based membranes [56-59]. On the other hand, to the best knowledge, this is first study about the investigation of molecular filtration capability of CA nanofibers and its CD modified type by "click" chemistry. From our results, it can be concluded that, the surface modification of electrospun CA nanofibers with CD molecules improved the molecular filtration potential by utilizing from the inclusion complexation property of CDs. The "click" chemistry is a quite new and promising method for the functionalization of electrospun nanofibers. In our study, better adsorption efficiency was obtained for CD modified CA nanofibers compared to untreated one during the removing test. However, the adsorbed amount of PAH or other organic compounds can be enhanced by grafting higher amount of $\mathrm{CD}$ on the nanofiber surface using "click" chemistry.

\section{Conclusion}

In this study, the permanent grafting of $C D$ molecules on the electrospun CA nanofibers was achieved by using "click" chemistry. First, $\beta-C D$ was modified so as to be azide- $\beta-C D$. At the same time, CA nanofibers were produced via electrospinning and they were treated chemically to be propargyl-terminated CA nanofibers. Then, "click" reaction was performed to graft the $\beta$-CD molecules on the surface of CA nanofibers. The morphological characterizations of nanofibers were carried out by SEM technique. It was revealed that, the CD modified CA nanofibers have rougher and irregular surface when it was compared with pristine CA nanofibers. The existence of the $C D$ molecules on the nanofiber surface was proved by using ATR-FTIR and XPS analyses. The filtration capability of CD grafted CA nanofibers was investigated by the removal of phenanthrene from its aqueous solution. For comparison, filtration test of pristine CA nanofibers was also performed. It was observed that, CA-CD nanofibers adsorbed higher amount of phenanthrene compared to CA nanofibers due to the inclusion complexation capability of $\mathrm{CD}$ molecules. We have also checked that, the fibrous structure of nanofibers was protected after the filtration test. In brief, our results indicate that $C D$ functionalized $C A$ nanofibers would have potential to be used as molecular filters for the purpose of water purification and waste water treatment by integrating the high surface area of nanofibers with inclusion complexation property of CD molecules. Moreover, "click" chemistry would be a promising candidate for the modification of nanofibers surface with various functional groups and moieties to benefit from the potentials of nanofibers more efficiently in their applications.

\section{Acknowledgements}

Dr. T. Uyar acknowledges TUBITAK-The Scientific and Technological Research Council of Turkey (project \#110M612) for funding the research. Dr. T. Uyar also acknowledges EU FP7-PEOPLE-2009RG Marie Curie-IRG (NANOWEB, PIRG06-GA-2009-256428) and The Turkish Academy of Sciences - Outstanding Young Scientists Award Program (TUBA-GEBIP) for partial funding. A. Celebioglu acknowledges TUBITAK-BIDEB for the national Ph.D. scholarship.

\section{References}

[1] S. Ramakrishna, K. Fujihara, W. Teo, T. Lim, Z. Ma, An Introduction to Electrospinning and Nanofibers, World Scientific Publishing Company, 2005.

[2] J.H. Wendorff, S. Agarwal, A. Greiner, Electrospinning: Materials, Processing, and Applications, Wiley-VCH, Germany, 2012

[3] V. Thavasi, G. Singh, S. Ramakrishna, Electrospun nanofibers in energy and environmental applications, Energ. Environ. Sci. 1 (2008) 205-221.

[4] C. Srisitthiratkul, W. Yaipimai, V. Intasant, Environmental remediation and super hydrophilicity of ultrafine antibacterial tungsten oxide-based nanofibers under visible light source, Appl. Surf. Sci. 259 (2012) 349-355.

[5] K. Yoon, B.S. Hsiao, B. Chu, Functional nanofibers for environmental applications, J. Mater. Chem. 18 (2008) 5326-5334.

[6] R.S. Barhate, S. Ramakrishna, Nanofibrous filtering media: filtration problems and solutions from tiny materials, J. Membr. Sci. 296 (2007) 1-8.

[7] T. Uyar, R. Havelund, Y. Nur, A. Balan, J. Hacaloglu, L. Toppare, F. Besenbacher, P. Kingshott, Cyclodextrin functionalized poly(methyl methacrylate)(PMMA) electrospun nanofibers for organic vapors waste treatment, J. Membr. Sci. 365 (2010) 409-417.

[8] E. Scholten, L. Bromberg, G.C. Rutledge, T.A. Hatton, Electrospun polyurethane fibers for absorption of volatile organic compounds from air, ACS Appl. Mater. Interface. 3 (2011) 3902-3909.

[9] Z. Ma, M. Kotaki, S. Ramakrishna, Surface modified nonwoven polysulphone (PSU) fiber mesh by electrospinning: a novel affinity membrane, J. Membr. Sci. 272 (2006) 179-187.

[10] Y. Mei, C. Yao, K. Fan, X. Li, Surface modification of polyacrylonitrile nanofibrous membranes with superior antibacterial and easy-cleaning properties through hydrophilic flexible spacers, J. Membr. Sci. 417-418 (417) (2012) 20-30.

[11] P.K. Neghlani, M. Rafizadeh, F.A. Taromi, Preparation of aminatedpolyacrylonitrile nanofiber membranes for the adsorption of metal ions: comparison with microfibers, J. Hazard. Mater. 186 (2011) 182-189.

[12] M. Stephen, N. Catherine, M. Brenda, K. Andrew, P. Leslie, G. Corrine Oxolane-2,5-dione modified electrospun cellulose nanofibers for heavy metals adsorption, J. Hazard. Mater. 192 (2011) 922-927.

[13] J. Niu, J. Xu, Y. Dai, J. Xu, H. Guo, K. Sun, R. Liu, Immobilization of horseradish peroxidase by electrospun fibrous membranes for adsorption and degradation of pentachlorophenol in water, J. Hazard. Mater. 246/247 (2013) 119-125. 
[14] J. Szejtli, Introduction and general overview of cyclodextrin chemistry, Chem. Rev. 98 (1998) 1743-1754.

[15] A. Hedges, Industrial applications of cyclodextrins, Chem. Rev. 98 (1998) 2035-2044.

[16] E.M. Del Valle, Cyclodextrins and their uses: a review, Process Biochem. 39 (2004) 1033-1046.

[17] D. Landy, I. Mallard, A. Ponchel, E. Monflier, S. Fourmentin, Remediation technologies using cyclodextrins: an overview, Environ. Chem. Lett. 10 (2012) $225-237$.

[18] W.C.E. Schofield, C.D. Bain, J.P.S. Badyal, Cyclodextrin-functionalized hierarchical porous architectures for high-throughput capture and release of organic pollutants from wastewater, Chem. Mater. 24 (2012) 1645-1653.

[19] G. Crini, M. Morcellet, Synthesis and applications of adsorbents containing cyclodextrins, J. Sep. Sci. 25 (2002) 789-813.

[20] N. Morin-Crini, G. Crini, Environmental applications of water-insolublecyclodextrin-epichlorohydrin polymers, Prog. Polym. Sci. 38 (2013) 344-368.

[21] T. Uyar, R. Havelund, J. Hacaloglu, F. Besenbacher, P. Kingshott, Functional electrospun polystyrene nanofibers incorporating $\alpha-, \beta-$, and $\gamma$-cyclodextrins: comparison of molecular filter performance, ACS Nano 4 (2010) 5121-5130.

[22] T. Uyar, R. Havelund, Y. Nur, J. Hacaloglu, F. Besenbacher, P. Kingshott, Molecular filters based on cyclodextrin functionalized electrospun fibers, J. Membr. Sci. 332 (2009) 129-137.

[23] E.S. Abdel-Halim, M.M.G. Fouda, I. Hamdy, F.A. Abdel-Mohdy, S.M. El-Sawy, Incorporation of chlorohexidin diacetate into cotton fabrics grafted with glycidyl methacrylate and cyclodextrin, Carbohyd. Polym. 79 (2010) 47-55.

[24] B. Martel, P. Le Thuaut, S. Bertini, G. Crini, M. Bacquet, G. Torri, M. Morcellet, Grafting of cyclodextrins onto polypropylene nonwoven fabrics for the manufacture of reactive filters. III. Study of the sorption properties, J. Appl. Polym. Sci. 85 (2002) 1771-1778

[25] P.L. Nostro, L. Fratoni, F. Ridi, P. Baglioni, Surface treatments on Tencel fabric: grafting with cyclodextrin, J. Appl. Polym. Sci. 88 (2003) 706-715.

[26] R. Romi, P.L. Nostro, E. Bocci, F. Ridi, P. Baglioni, Bioengineering of a cellulosic fabric for insecticide delivery via grafted cyclodextrin, Biotechnol. Progr. 21 (2008) 1724-1730.

[27] N. Blanchemain, S. Haulon, E. Marcon-Bachari, M. Traisnel, C. Neut, J. KirkPatrick, M. Morcellet, H. Hildebrand, B. Martel, Vascular prostheses with controlled release of antibiotics Part 1 . Surface modification with cyclodextrins of PET prostheses, Biomol. Eng. 24 (2007) 149-153.

[28] L. Ducoroy, B. Martel, B. Bacquet, M. Morcellet, Ion exchange textiles from the finishing of PET fabrics with cyclodextrins and citric acid for the sorption of metallic cations in water, J. Incl. Phenom. Macro. 57 (2007) 271-277.

[29] N. Blanchemain, T. Laurent, S. Haulon, M. Traisnel, C. Neut, J. Kirkpatrick, M. Morcellet, H.F. Hildebrand, B. Martel, In vitro study of a HP gamma-cyclodextrin grafted PET vascular prosthesis for application as anti-infectious drug delivery system, J. Incl. Phenom. Macro. 57 (2007) 675-681.

[30] B. Martel, M. Morcellet, D. Ruffin, L. Ducoroy, M. Weltrowski, Finishing of polyester fabrics with cyclodextrins and polycarboxylic acids as crosslinking agents, J. Incl. Phenom. Macro. 44 (2002) 443-446.

[31] F. Kayaci, Z. Aytac, T. Uyar, Surface modification of electrospun polyester nanofibers with cyclodextrin polymer for the removal of phenanthrene from aqueous solution, J. Hazard. Mater. 261 (2013) 286-294.

[32] W.H. Binder, R. Sachsenhofer, Click chemistry in polymer and materials science, Macromol. Rapid Commun. 28 (2007) 15-54.

[33] J.E. Moses, A.D. Moorhouse, The growing applications of click chemistry, Chem. Soc. Rev. 36 (2007) 1249-1262.

[34] G.D. Fu, L.Q. Xu, F. Yao, Smart Nanofibers from Combined Living Radical Polymerization, click Chemistry and Electrospinning, ACS Appl. Mater. Interface. 1 (2009) 239-243.

[35] Z. Chang, Y. Xu, X. Zhao, Q. Zhang, D. Chen, Grafting poly(methyl methacrylate) onto polyimide nanofibers via click reaction, ACS Appl. Mater. Interface. 1 (2009) 2804-2811.

[36] H. Yang, Q. Zhang, B. Lin, G. Fu, X. Zhang, L. Guo, Thermo-sensitive electrospun fibers prepared by a sequential thiolene click chemistry approach, J. Polym. Sci. A Polym. Chem. 50 (2012) 4182-4190.

[37] A. Lancuški, F. Bossard, S. Fort, Carbohydrate-decorated PCL fibers for specific protein adhesion, Biomacromolecules 14 (2013) 1877-1884
[38] Y.-C. Qian, N. Ren, X.-J. Huang, C. Chen, A.-G. Yu, Z.-K. Xu, Glycosylation of polyphosphazene nanofibrous membrane by click chemistry for protein recognition, Macromol. Chem. Phys. 214 (2013) 1852-1858.

[39] A.K. Haritash, C.P. Kaushik, Biodegradation aspects of polycyclic aromatic hydrocarbons (PAHs): a review, J. Hazard. Mater. 169 (2009) 1-15.

[40] S.K. Samanta, O.V. Singh, R.K. Jain, Polycyclic aromatic hydrocarbons: environmental pollution and bioremediation, Trends Biotechnol. 20 (2002) 243-248.

[41] K. Yang, L. Zhu, B. Xing, Adsorption of polycyclic aromatic hydrocarbons by carbon nanomaterials, Environ. Sci. Technol. 40 (2006) 1855-1861.

[42] A. Walcarius, L. Mercier, Mesoporous organosilica adsorbents: nanoengineered materials for removal of organic and inorganic pollutants, J. Mater. Chem. 20 (2010) 4478-4511

[43] K. Tungala, P. Adhikary, S. Krishnamoorth, Trimerization of $\beta$-cyclodextrin through the click reaction, Carbohyd. Polym. 95 (2013) 295-298.

[44] V.I. Bhoi, C.N. Murthy, Aqueous solubilization of [60] fullerene by selectively modified $\beta$-cyclodextrin, fullerenes, nanotubes, Carbon Nanostruct. 19 (2011) 668-676.

[45] R. Ranjan, W.J. Brittain, Combination of living radical polymerization and click chemistry for surface modification, Macromolecules 40 (2007) 6217-6223.

[46] H. Toiserkani, G. Yilmaz, Y. Yagci, L. Torun, Functionalization of polysulfones by click chemistry, Macromol. Chem. Phys. 211 (2010) 2389-2395.

[47] A. Uliniuca, M. Popa, E. Drockenmullera, F. Boisson, D. Leonard, T. Hamaide Toward tunable amphiphilic copolymers via CuAAC click chemistry of oligocaprolactones onto starch backbone, Carbohyd. Polym. 96 (2013) 259-269.

[48] T. Cai, W.J. Yang, Z. Zhang, X. Zhu, K.-G. Neoh, E.-T. Kang, Preparation of stimuli-responsive hydrogel networks with threaded b-cyclodextrin endcapped chains via combination of controlled radical polymerization and click chemistry, Soft Matter 8 (2012) 5612-5620.

[49] R. Barbar, A. Durand, J.J. Ehrhardt, J. Fanni, M. Parmentier, Physicochemical characterization of a modified cellulose acetate membrane for the design of oil-in-water emulsion disruption devices, J. Membr. Sci. 310 (2008) 446-454.

[50] A.A. Qaiser, M.M. Hyland, D.A. Patterson, Surface and charge transport characterization of polyaniline-cellulose acetate composite membranes, J. Phys. Chem. B 115 (2011) 1652-1661.

[51] C. Raveler, E. Peyrin, A. Villet, C. Grosset, A. Ravel, J. Alary, Chromatographic study of PAH- $\beta-C D$ inclusion complexes using a binary mixture and cyanostationary phase, Chromatographia 53 (2001) 624-628.

[52] J. Rima, E. Aoun, K. Hanna, Effect of n-alkyl chain length on the complexation of phenanthrene and 9-alkyl-phenanthrene with $\beta$-cyclodextrin, Spectrochim. Acta A 60 (2004) 1515-1521.

[53] T. Badr, K. Hanna, C. de Brauer, Enhanced solubilization and removal of naphthalene and phenanthrene by cyclodextrins from two contaminated soils, J. Hazard. Mater. 112 (2004) 215-223.

[54] G. Chalumot, C. Yao, V. Pino, J.L. Anderson, Determining the stoichiometry and binding constants of inclusion complexes formed between aromatic compounds and $\beta$-cyclodextrin by solid-phase microextraction coupled to high-performance liquid chromatography, J. Chromatogr. A 1216 (2009) 5242-5248.

[55] R. Orprecio, C.H. Evans, Polymer-immobilized cyclodextrin trapping of mode organic pollutants in flowing water streams, J. Appl. Polym. Sci. 90 (2003) 2103-2110.

[56] X. Li, Y. Zhu, T. Wu, S. Zhang, P. Christie, Using a novel petroselinic acid embedded cellulose acetate membrane to mimic plant partitioning and in vivo uptake of polycyclic aromatic hydrocarbons, Environ. Sci. Technol. 44 (2010) 297-301.

[57] Y. Tao, B. Xue, S. Yao, J. Deng, Z. Gui, Triolein embedded cellulose acetate membrane as a tool to evaluate sequestration of PAHs in lake sediment core at large temporal scale, Environ. Sci. Technol. 46 (2012) 3851-3858.

[58] R. Ke, Y. Xu, Z. Wang, S.U. Khan, Estimation of the uptake rate constants for polycyclic aromatic hydrocarbons accumulated by semipermeable membrane devices and triolein-embedded cellulose acetate membrane, Environ. Sci. Technol. 40 (2006) 3906-3911.

[59] Y. Tao, S. Zhang, Z. Wang, R. Ke, X.-Q. Shan, P. Christie, Biomimetic accumulation of PAHs from soils by triolein-embedded cellulose acetate membranes (TECAMs) to estimate their bioavailability, Water Res. 42 (2008) 754-762. 